\title{
Vancomycin-resistant Staphylococcus aureus isolated from camel meat and slaughterhouse workers in Egypt
}

\author{
Khaled Al-Amery ${ }^{1}$, Mahmoud Elhariri ${ }^{1}$, Alaa Elsayed ${ }^{2}$, Gihan El-Moghazy ${ }^{2}$, Rehab Elhelw ${ }^{1}$, Heba El-Mahallawy ${ }^{3}$,
} Mohamed El Hariri ${ }^{4}$ and Dalia Hamza ${ }^{5^{*}}$ (D)

\begin{abstract}
Background: The emergence of vancomycin-resistant Staphylococcus aureus (VRSA) represents a challenge for the treatment of staphylococcal infections in both human and animals worldwide. Although VRSA has been detected in several animal species worldwide, data on the bacterial prevalence in dromedary camels and workers in camel slaughterhouses are scarce.

Methods: We investigated meat samples from 200 dromedary camel carcasses from three different abattoirs that were being prepared to be sent to the markets. Twenty hand swabs were voluntarily collected from the workers in the same abattoirs. Isolation and identification of the bacterial specimens from the samples were performed using conventional cultural techniques and biochemical identification and were confirmed by PCR amplification of the nuc gene. Antimicrobial susceptibility against nine antimicrobial agents commonly used in human and camels was tested using the disc diffusion method, and genetic analysis was performed by evaluating the mecA gene in phenotypically oxacillin (OXA)- and cefoxitin (FOX)-resistant isolates. The resistance of S. aureus to vancomycin (VAN) was tested by broth microdilution and confirmed by PCR targeting the vanA and vanB genes. The vanA and vanB genes were sequenced.
\end{abstract}

Result: S. aureus was detected in both camel meat (29/200, 14.5\%) and in abattoir workers (11/20, 55\%). Of the collected samples, 27\% (8/29, camel) and 54\% (6/11, human) were identified as VRSA.

All VRSA isolates carried both the vanA and vanB genes. Additionally, all VRSA isolates were also classified as methicillin-resistant S. aureus (MRSA). The vanA amplicons of the isolates from human and camel meat were homologous and clustered with a Chinese reference isolate sequence.

Conclusion: This study demonstrated that VRSA is present in camel abattoirs in Egypt. Zoonotic transmission between animals and human is probable and reflects both a public health threat and a food safety concern.

Keywords: Dromedary camels, Human, S. aureus, VRSA, Abattoir, Egypt

\section{Background}

Staphylococcus aureus (S. aureus) is one of the most common microorganisms that colonize the nasal cavity and/or the external body surfaces of human and various animal species. S. aureus may be present either as commensal bacteria or pathogenic bacteria, which can cause multiple infectious diseases [1]. Since the first report of

\footnotetext{
* Correspondence: daliahamza@cu.edu.eg

${ }^{5}$ Department of Zoonoses, Faculty of Veterinary Medicine, Cairo University, PO Box 12211, Giza, Cairo, Egypt

Full list of author information is available at the end of the article
}

a methicillin-resistant S. aureus (MRSA) strain in 1961 from a human patient, attention has been paid to its public health significance, leaving vancomycin (VAN) as the antibiotic of choice for the treatment of many infections [2]. However, in July 2002, the situation changed when the Centers for Disease Control and Prevention (CDC) in the USA documented the first sample of S. aureus that was resistant to both VAN and methicillin [3].

In the Middle East, the dromedary camel (Camelus dromedarius, one-humped camel) is an important livestock species adapted to hot and dry environments. In 
Egypt, camels are frequently slaughtered, and their meat is consumed by human year-round.

Camels were formerly thought not to be affected by most of the diseases commonly impacting livestock; however, recent data have confirmed their susceptibility to a high number of pathogens, and camels are currently believed to act as a carrier or reservoir for the transmission of several transboundary animal diseases and zoonoses [4].

Epidemiological studies on resistant $S$. aureus in camels usually focus on the bacterial prevalence in milk [5-7]; few studies have discussed anthropozoonotic transmission vs. zooanthroponotic transmission due to contact with camels by slaughterhouse employees or camel breeders.

In Egypt, no data are available about the distribution, colonization, and transmission of resistant $S$. aureus in camels and their human contacts. This study was carried out to determine the occurrence of VRSA among dromedary camels and slaughterhouse workers and to study the probable zoonotic risk.

\section{Materials and methods Sample collection Camel meat samples}

Two hundred meat samples were collected from 200 camel carcasses (one sample from each animal) after slaughter from three different abattoirs in the greater Cairo area (GCA); samples were collected throughout 2017.

\section{Human hand swabs}

Hand swabs were collected from 20 adult male slaughterhouse workers. All workers were informed about the nature of the experiment. Sample collection was performed after handling meat for no less than 1 hour. All the workers were clinically free from any bacterial skin infections at the time of examination. Workers were asked not to wash their hands before sampling.

The palm surfaces of both hands were swabbed with cotton tipped swabs moistened with sterile saline. The entire palm surface was swabbed perpendicularly. We avoided obtaining samples from interdigital areas. Sterile gloves were used during sampling to minimize sample cross-contamination. Sample blanks consisted of swabs that had been moistened and placed directly in sterile 15-ml polypropylene tubes. Following collection, all samples were transported on ice to the Faculty of Veterinary Medicine, Cairo University, where they were processed for Staphylococcus spp. isolation.

\section{Isolation and identification of S. aureus}

One gram of meat samples from the animals and the hand swabs from the workers were placed into $9 \mathrm{ml}$ of brain heart infusion broth (Oxoid, Hampshire, UK) and incubated at $37^{\circ} \mathrm{C}$ for $24 \mathrm{~h}$. Two loopfuls from each broth sample were plated on mannitol salt agar (Oxoid, Hampshire, UK) and 5\% sheep blood agar (Oxoid Ltd., Hampshire, UK) and incubated aerobically at $37^{\circ} \mathrm{C}$ for $24 \mathrm{~h}$.

The typical Staphylococcus spp. colonies were further examined by gram staining and traditional biochemical methods according to Quinn [8] and confirmed as $S$. aureus by both the latex agglutination test using a Staphytect Plus kit (Oxoid, UK); nuc gene detection was performed according to Louie et al., 2002 [9].

At least two colonies from each positive plate were maintained on brain heart infusion broth for further testing and PCR analysis.

\section{Antimicrobial susceptibility test Disc agar diffusion test}

The Kirby-Bauer disc diffusion technique was performed to determine the antibiotic resistance profile of the isolates. After overnight incubation on Mueller-Hinton agar at $37^{\circ} \mathrm{C}$ (Oxoid Ltd., Hampshire, UK), the inhibition zones were measured, and the interpretation was carried out according to the Clinical and Laboratory Standards Institute (CLSI) guidelines [10]. S. aureus isolates were tested against nine different antibiotics with the following corresponding concentrations: chloramphenicol (CHL) $(30 \mu \mathrm{g} /$ disc), clindamycin (CLI) $(2 \mu \mathrm{g} /$ disc), erythromycin (ERY) $(15 \mu \mathrm{g} / \mathrm{disc})$, novobiocin (NV) $(30 \mu \mathrm{g} / \mathrm{disc})$, ofloxacin (OFX) $(5 \mu \mathrm{g} / \mathrm{disc})$, cefoxitin (FOX) $(30 \mu \mathrm{g} / \mathrm{disc})$, oxacillin (OXA) $(1 \mu \mathrm{g} / \mathrm{disc})$, trimethoprim-sulfamethoxazole (SXT) $(23.75 \mu \mathrm{g} / \mathrm{disc})$ and VAN $(30 \mu \mathrm{g} /$ disc $)$. The discs were purchased from Oxoid Ltd. (Hampshire, UK).

\section{Determination of minimum inhibitory concentration}

The minimum inhibitory concentration (MIC) values of VAN were determined by a broth microdilution method using cation-adjusted Mueller-Hinton broth (Oxoid Ltd., Hampshire, UK) and VAN standard antibiotic (Sigma Aldrich). The procedure and interpretation of the results were performed according to the CLSI guidelines [10]. The laboratory breakpoints were as follows: vancomycin-susceptible $S$. aureus $(\mathrm{VSSA})=$ vancomycin MIC $<2 \mu \mathrm{g} / \mathrm{ml}$; and VRSA = vancomycin MIC $>16 \mu \mathrm{g} / \mathrm{ml}$.

\section{DNA extraction}

All S. aureus isolates were grown on mannitol salt agar at $37^{\circ} \mathrm{C}$ overnight. A single bacterial colony from each plate was picked and suspended in $200 \mu \mathrm{l}$ deionized distilled water. Genomic DNA was extracted using the QIAamp Mini DNA Extraction Kit (Qiagen, Hilden, Germany). 
Table 1 List of primer pairs and cycling conditions for the nuc, mecA, vanA and $v a n B$ genes used in this study

\begin{tabular}{|c|c|c|c|c|}
\hline Target gene & nuc & mecA & $\operatorname{van} A$ & $\operatorname{van} B$ \\
\hline Primer pairs & $\begin{array}{l}\text { 5'-GCGATTGATGGTGATACGGTT- } \\
\text { 3' } \\
\text { 5'-AGCCAAGCCTTGACGAACTA } \\
\text { AAGC-3' }\end{array}$ & $\begin{array}{l}\text { 5'-AGAAGATGGTATGTGGAAGT } \\
\text { TAG--3' } \\
\text { 5'-ATGTATGTGCGATTGTATTGC- } \\
3^{\prime}\end{array}$ & $\begin{array}{l}\text { 5'- GGCAAGTCAGGTGAAGATG- } \\
\text { 3' } \\
\text { 5' ATCAAGCGGTCAATCAGTTC- } \\
3^{\prime}\end{array}$ & $\begin{array}{l}\text { 5' GTG ACA AAC CGG AGG CGA } \\
\text { GGA } 3^{\prime} \\
\text { 5' CCG CCA TCC TCC TGC AAA } \\
\text { AAA-3' }\end{array}$ \\
\hline $\begin{array}{l}\text { PCR product } \\
\text { (bp) }\end{array}$ & 270 & 583 & 713 & 430 \\
\hline $\begin{array}{l}\text { Cycling } \\
\text { conditions }\end{array}$ & $\begin{array}{l}\text { - Initial denaturation at } 94^{\circ} \mathrm{C} \text { for } \\
5 \text { min. } \\
\text { ( } 35 \text { cycles): } \\
\text { - Denaturation at } 94^{\circ} \mathrm{C} \text { for } 30 \mathrm{~s} \text {. } \\
\text { - Annealing at } 55^{\circ} \mathrm{C} \text { for } 30 \mathrm{~s} . \\
\text { - Polymerization at } 72^{\circ} \mathrm{C} \text { for } 1 \\
\text { min. } \\
\text { - Final extension step at } 72^{\circ} \mathrm{C} \\
\text { and } 10 \text { min. } \\
\text { Louie et al., } 2002 \text { [9]. }\end{array}$ & $\begin{array}{l}\text { - Initial denaturation at } 94^{\circ} \mathrm{C} \\
\text { for } 5 \text { min. } \\
\text { ( } 40 \text { cycles): } \\
\text { - Denaturation at } 94^{\circ} \mathrm{C} \text { for } 30 \mathrm{~s} \text {. } \\
\text { - Annealing at } 57^{\circ} \mathrm{C} \text { for } 45 \mathrm{~s} \text {. } \\
\text { - Polymerization at } 72^{\circ} \mathrm{C} \text { for } 30 \\
\text { s. } \\
\text { - Final extension step at } 72^{\circ} \mathrm{C} \\
\text { and } 5 \text { min. } \\
\text { Azimian et al., } 2012 \text { [12]. }\end{array}$ & $\begin{array}{l}\text { - Initial denaturation at } 94^{\circ} \mathrm{C} \\
\text { for } 5 \text { min. } \\
\text { ( } 40 \text { cycles): } \\
\text { - Denaturation at } 94^{\circ} \mathrm{C} \text { for I } \\
\text { min. } \\
\text { - Annealing at } 55^{\circ} \mathrm{C} \text { for } 1 \text { min. } \\
\text { - Polymerization at } 72^{\circ} \mathrm{C} \text { for } 2 \\
\text { min. } \\
\text { - Final extension step at } 72^{\circ} \mathrm{C} \\
\text { and } 5 \text { min. } \\
\text { Azimian et al., } 2012[12] .\end{array}$ & $\begin{array}{l}\text { - Initial denaturation at } 94^{\circ} \mathrm{C} \text { for } \\
10 \text { min. } \\
\text { ( } 30 \text { cycles): } \\
\text { - Denaturation step at } 94^{\circ} \mathrm{C} \text { and } \\
30 \mathrm{~s} \text {. } \\
\text { - Annealing step at } 50^{\circ} \mathrm{C} \text { and a } \\
45 \mathrm{~s} \text {. } \\
\text { - Polymerization at } 72{ }^{\circ} \mathrm{C} \text { for } 30 \\
\text { s. } \\
\text { - Final extension step at } 72^{\circ} \mathrm{C} \\
\text { and } 10 \text { min. } \\
\text { Saadat et al., } 2014[11] .\end{array}$ \\
\hline
\end{tabular}

\section{Molecular confirmation of S. aureus, MRSA and VRSA isolates}

(i) Molecular confirmation was performed by amplification of the $S$. aureus-specific nuc gene to identify positive $S$. aureus isolates [9].

(ii) PCR identification of the $m e c A$ gene was performed in phenotypically FOX- and OXA-resistant isolates (25 isolates).

(iii) PCR amplification of $v a n A$ and $v a n B$ genes encoding VAN resistance was conducted in phenotypically VAN-resistant isolates (14 isolates).

Staphylococcus aureus ATCC 29213 and Enterococcus faecalis ATCC 29212 strains were used as VAN-susceptible controls [11]. VAN-resistant Enterococcus faecium ATCC 51559 was used as a vanA-positive control strain, and E. faecalis ATCC 51299 was used as a $v a n B$-positive control strain.

PCR amplification was performed using $3 \mu \mathrm{l}$ of the extracted bacterial DNA, $25 \mu \mathrm{l}$ of $2 \mathrm{X}$ DreamTaq DNA PCR Master Mix (Thermo Scientific, Waltham, USA), and $0.5 \mu \mathrm{l}$ of each primer at a concentration of $20 \mathrm{pmol}$; nuclease-free water was added up to $50 \mu \mathrm{l}$. The primer pairs and cycling conditions used in the PCRs are summarized in Table 1.
Fifteen microlitres of the amplification products were identified by electrophoresis in a $1.5 \%$ agarose gel (Sigma, Darmstadt, Germany) stained with $1 \mu \mathrm{g} / \mathrm{ml}$ of ethidium bromide (Sigma, Darmstadt, Germany) in $1 \mathrm{x}$ TAE buffer for $30 \mathrm{~min}$ before being visualized under UV light and photographed.

\section{Sequencing and nucleotide sequence analysis}

The amplification products of four VRSA isolates (two camels and two human VRSA-positive isolates) were sequenced at Promega Lab Technology (Madison, USA) using the forward and reverse primers of the vanA and $v a n B$ genes after being purified from the gel using a QIAquick gel extraction kit (Qiagen, Hilden, Germany) according to the manufacturer's instructions. The sequence was deposited in the GenBank database under the accession numbers for the vanA gene (MH744353 and MH744354 for the camel meat isolates and MH744355 and MH744356 for the human isolates). The accession numbers for the $v a n B$ gene are MK087830 and MK087831 for the camel meat isolates and MK087832 and MK095504 for the human isolates.

The nucleotide sequences of the vanA isolates were compared with the sequences available in the public domains using the National Center for Biotechnology Information (NCBI) Basic Local Alignment Search Tool

Table 2 Prevalence of S. aureus among the samples from camel meat and hands of the workers

\begin{tabular}{|c|c|c|c|c|c|c|c|c|}
\hline \multirow{2}{*}{$\begin{array}{l}\text { Source and type } \\
\text { of the sample }\end{array}$} & \multicolumn{2}{|c|}{ Abattoir (1) } & \multicolumn{2}{|c|}{ Abattoir (2) } & \multicolumn{2}{|c|}{ Abattoir (3) } & \multirow{2}{*}{$\begin{array}{l}\text { Total } \\
\text { samples } \\
\text { examined }\end{array}$} & \multirow{2}{*}{$\begin{array}{l}\text { S. aureus } \\
\text { positive } \\
\text { no. (\%) }\end{array}$} \\
\hline & $\begin{array}{l}\text { Sample } \\
\text { no. }\end{array}$ & $\begin{array}{l}\text { S. aureus positive no. } \\
\text { (\%) }\end{array}$ & $\begin{array}{l}\text { Sample } \\
\text { no. }\end{array}$ & $\begin{array}{l}\text { S. aureus positive no. } \\
\text { (\%) }\end{array}$ & $\begin{array}{l}\text { Sample } \\
\text { no. }\end{array}$ & $\begin{array}{l}\text { S. aureus positive no. } \\
\text { (\%) }\end{array}$ & & \\
\hline $\begin{array}{l}\text { Camel meat } \\
\text { samples }\end{array}$ & 62 & $8(12.9 \%)$ & 70 & $10(14.3 \%)$ & 68 & 11 (16.2\%) & 200 & 29 (14.5\%) \\
\hline $\begin{array}{l}\text { Human hand } \\
\text { swabs }\end{array}$ & 6 & $3(50 \%)$ & 7 & $4(57.1 \%)$ & 7 & $4(57.1 \%)$ & 20 & 11 (55\%) \\
\hline
\end{tabular}




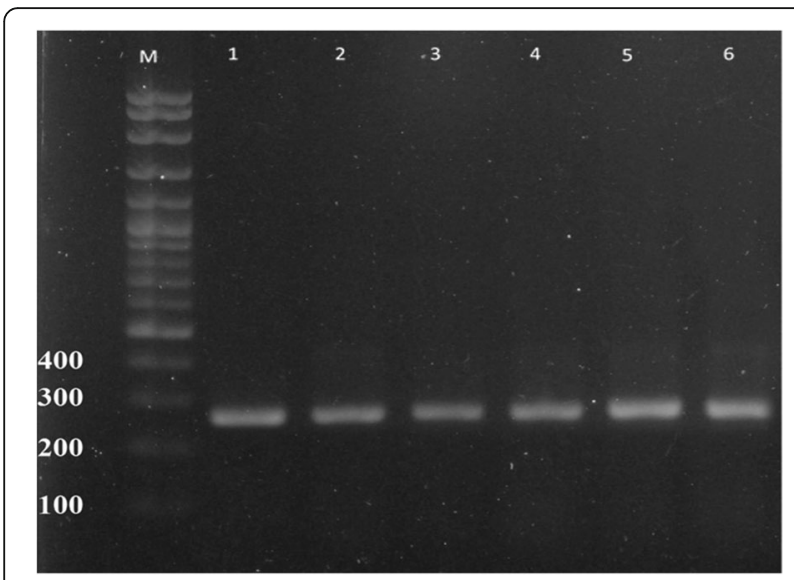

Fig. 1 Amplified PCR products of nuc gene at (270 bp). Lane M: 100 bp ladder, Lane 1 to 6 positive to Staphylococcus aureus

(BLAST) server. Sequences were downloaded and imported into BIOEDIT version 7.0.1.4 for multiple alignments according to their deduced amino acid sequences using the CLUSTALW program of BIOEDIT.

Nucleotide sequence analysis was performed using MEGA version 7 with the neighbour-joining approach. Bootstrap analysis was performed with 1000 resamplings.

\section{Statistical analysis}

PASW statistics by SPSS 18.0 (SPSS Inc., Chicago, IL, USA) was used to analyse the data. Chi-square and Fisher's exact tests were used to compare carriage rates between different abattoirs and hosts and sensitivity to different antibiotics. Differences were considered statistically significant if the $P$ value was $<0.05$.

\section{Ethics statement}

Protocols for the collection of samples were conducted according to the guidelines of the Institutional Animal Care and Use Committee (IACUC) of the Faculty of Veterinary Medicine, Cairo University, Egypt (VetCU05192019041).

Oral consent was obtained from each abattoir worker who participated in the study after they were educated on the use of the hand swab samples.

\section{Results}

Out of the 200 examined meat samples and 20 hand swabs from human, S. aureus was isolated from 29/200 (14.5\%) and 11/20 (55\%) samples, respectively (Table 2). Isolates were identified as $S$. aureus by positivity in the mannitol fermentation test, catalase test, coagulase (tube) test, acetoin formation test and DNase test. Moreover, these isolates showed positive results using both the Staphytect Plus kit and nuc gene detection. (Fig. 1).

The detection rates of $S$. aureus in the different abattoirs did not differ significantly $(P=0.868$ for camel meat and 1.000 for human hand swabs). However, the detection rates of $S$. aureus in camel meat samples and human hand swabs showed that $S$. aureus occurred more frequently in the samples from human (55\% vs. 14.5\%; $P<0.001)$.

The most common resistance pattern was CHL-FOXOXA-CLI- SXT-ERY-NV for the camel isolates $(P=$ $0.000)$ and ERY-FOX-OXA-VAN-OFX-SXT for the isolates from human $(P=0.426)$ (Table 3$)$. All isolates that showed resistance to VAN were also resistant to FOX and OXA.

The mecA gene was amplified from all phenotypically FOX-, OXA- and VAN-resistant isolates (Fig. 2).

Of the $40 \mathrm{~S}$. aureus isolates examined, 14 isolates (35\%) were resistant to VAN, with a MIC> $>16 \mu \mathrm{g} / \mathrm{ml}$. Based on the MIC results, VRSA was detected in $27.6 \%$ $(8 / 29)$ of camel meat samples and $54.5 \%(6 / 11)$ of human hand swabs, without a significant relationship $(P=$ 0.111). (Table 4).

Both the $v a n A$ and $v a n B$ genes were amplified from all phenotypically VAN-resistant isolates (14/14,100\%) (Figs. 3, 4).

Comparing the sequences of the vanA genes revealed $100 \%$ homology between the four selected isolates from the camel meat and the hands of the workers in our study and the reference isolate $S$. aureus Cd6 from China, as shown in Fig. 5.

\section{Discussion}

Recently, the epidemiology of $S$. aureus and its newly emerged resistant strains has gained attention in both veterinary and human medicine, particularly because of their zoonotic potential. Although the emergence and

Table 3 Frequencies of resistance of $S$. aureus isolates from camel meat and from the hands of workers to singular antibiotics

\begin{tabular}{llllllllll}
\hline S. aureus isolates & $\mathrm{CHL}^{\mathrm{a}}$ & $\mathrm{CLI}$ & $\mathrm{ERY}^{\mathrm{a}}$ & $\mathrm{NV}^{\mathrm{a}}$ & $\mathrm{OFX}^{\mathrm{a}}$ & $\mathrm{FOX}^{\mathrm{a}}$ & $\mathrm{OXA}^{\mathrm{a}}$ & $\mathrm{SXT}^{\mathrm{a}}$ & VAN $^{\mathrm{a}}$ \\
\hline Camel $(n=29)$ & $26(89.7)^{*}$ & $20(69.0)$ & $17(58.6)$ & $17(58.6)^{*}$ & $2(6.9)$ & $25(86.2)$ & $25(86.2)$ & $19(65.5)$ & $8(27.6)$ \\
Human $(n=11)$ & $4(36.4)$ & $5(45.5)$ & $7(63.6)$ & $2(18.2)$ & $6(54.5)^{*}$ & $7(63.6)$ & $7(63.6)$ & $5(45.5)$ & $6(54.5)$ \\
Total $(n=40)$ & $30(75)$ & $25(62.5)$ & $24(60)$ & $19(47.5)$ & $8(20)$ & $32(80)$ & $28(70)$ & $24(60)$ & $14(35)$ \\
\hline
\end{tabular}

Abbreviations: CHL chloramphenicol, CLI clindamycin, ERY erythromycin, NV novobiocin, OFX ofloxacin, FOX cefoxitin, OXA oxacillin, SXT trimethoprimsulfamethoxazole, VAN vancomycin

${ }^{*}$ Antimicrobial resistance of $S$. aureus isolates towards CHL, NV and OFX showed a significant dependence on the host $(P=0.001,0.022$ and 0.001, respectively) ${ }^{\mathrm{a}}$ Data presented as No. (\%) 


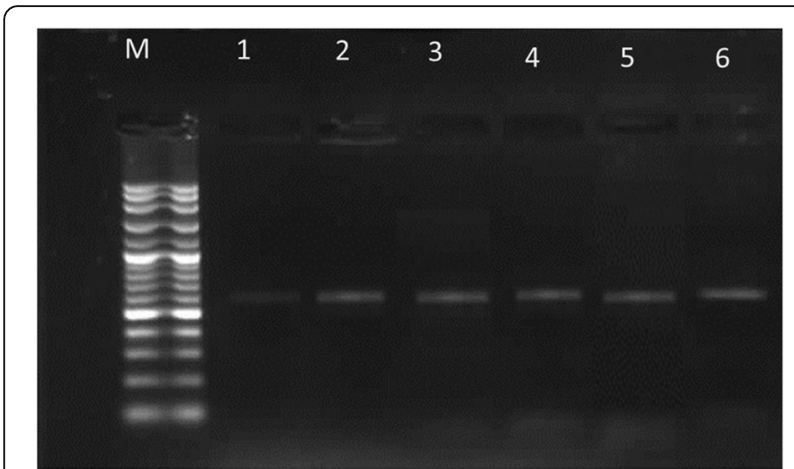

Fig. 2 Amplified PCR products of mecA gene at (583 bp). Lane M: 100 bp ladder, Lane 1 to 6 . Positive to mecA gene; results for 6 among the 25 isolates

spread of resistant Staphylococcus strains has been previously reported from apparently healthy pets [13] and pigs [14], there are no definitive data on its prevalence in apparently healthy camels or their role as carriers.

In this study, out of the 200 meat samples from 200 dromedary camels, $S$. aureus was isolated at a high rate $(14.5 \%, 29 / 200)$; it was also isolated from $55 \%(11 / 20)$ of the 20 slaughterhouse workers, who were working predominantly at the investigated abattoirs (Table 2).

Very similar S. aureus isolation rates $(11.7 \%)$ were reported in carcass swabs from abattoirs in Addis Ababa, Ethiopia [15]. However, the overall S. aureus prevalence in this study was lower than that reported from nasal samples from camels in Nigeria (20.7\%) and higher than that reported in human contacts $(11.5 \%)$ in the same study [16].

Over the past decade, the problem of antimicrobial resistance in the African continent has gained special interest. However, little is known about the real extent of the problem because surveillance for antimicrobial resistance is carried out in only a few countries [17]. In this study, all of the obtained $S$. aureus isolates showed different patterns of multi-resistance to the nine tested antimicrobials. The most common resistance patterns were CHL-FOX-OXA-CLI-SXT-ERY-NV for camel isolates and ERY-FOX-OXA-VAN-OFX-SXT for human isolates (Table 3). The emergence of such resistant strains plays an important role in therapeutic failure in

Table 4 The MIC results of VAN resistance in S. aureus isolates from dromedary camels and human

\begin{tabular}{|c|c|c|c|c|c|c|c|c|c|c|}
\hline \multirow[t]{3}{*}{ Source } & \multirow{3}{*}{$\begin{array}{l}\text { No. of } \\
\text { examined } \\
\text { samples }\end{array}$} & \multicolumn{8}{|c|}{ MIC $(\mu \mathrm{g} / \mathrm{ml})$} & \multirow{3}{*}{$\begin{array}{l}\text { Total } \\
\text { resistant } \\
\text { isolates }\end{array}$} \\
\hline & & \multirow[t]{2}{*}{0.5} & \multirow[t]{2}{*}{1} & \multirow[t]{2}{*}{2} & \multirow[t]{2}{*}{4} & \multirow[t]{2}{*}{8} & \multicolumn{3}{|c|}{ Resistant } & \\
\hline & & & & & & & 16 & 32 & 64 & \\
\hline Camel & 29 & 16 & 4 & 1 & - & - & 5 & 1 & 2 & $8(27.6 \%)$ \\
\hline Human & 11 & 2 & 2 & 1 & - & - & 2 & 1 & 3 & $6(54.5 \%)$ \\
\hline Total & 40 & 18 & 6 & 2 & - & - & 7 & 2 & 5 & $14(35 \%)$ \\
\hline
\end{tabular}

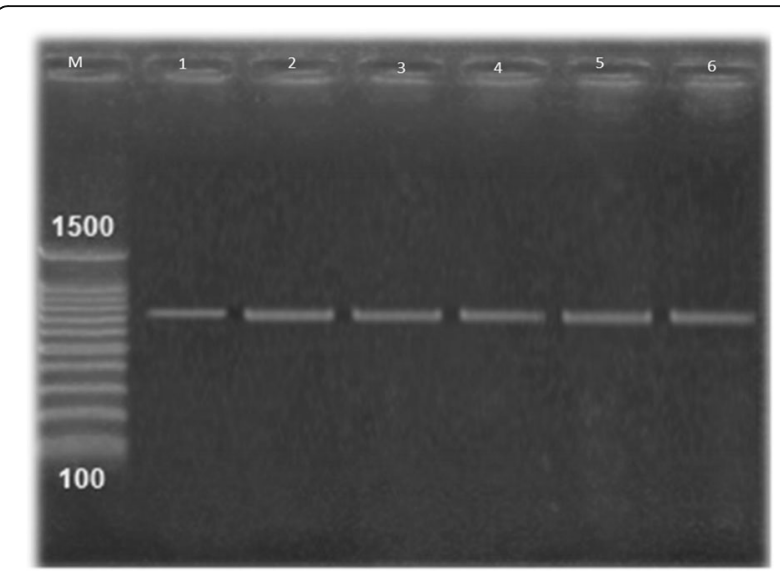

Fig. 3 Amplified PCR products of VanA gene at (713 bp). Lane M: 100 bp ladder, Lane 1: positive control. Lane 2 to 6 . Positive to vanA gene of VRSA isolates; results for 5 among the 14 VRSA isolates

both human and animal infections. The uncontrolled use of antibiotics in human and animals, together with poor diagnostic techniques and inappropriate prescribing by unqualified physicians, exacerbates the problem [18] and constitutes a great challenge for the prevention and control of this pathogen. The same resistance pattern was previously noted in MRSA isolates from an intensive care unit in Hyderabad, southern India, by using the disc diffusion method [16]. Moreover, recently in India, VRSA was identified in $16.7 \%$ of MRSA isolates obtained from buffalo nasal and skin samples by using the disc diffusion method [19].

In view of this antibiotic resistance, VAN is now a lastchoice antibiotic for the treatment of MRSA, and its use in human and animals is limited [19, 20]. Recently, due to the introduction of other alternative compounds, VAN is no longer an antibiotic of last resort; nevertheless, it is the most frequently used antibiotic in cases of staphylococcal infections [21]. In this study, the isolates showing resistance to VAN were also resistant to FOX

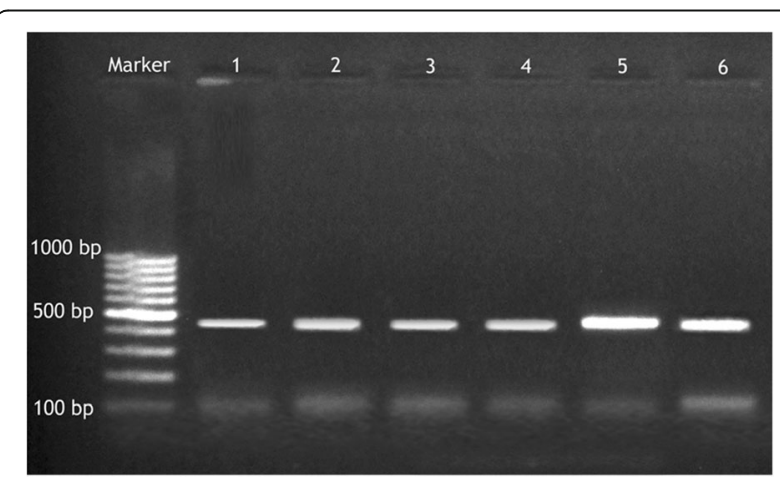

Fig. 4 Amplified PCR products of VanB gene at (430 bp). Lane M: 100 bp ladder, Lane 1, positive control, lane: 2 to6 positive to vanB gene of VRSA isolates; results for 5 among the 14 VRSA isolates 


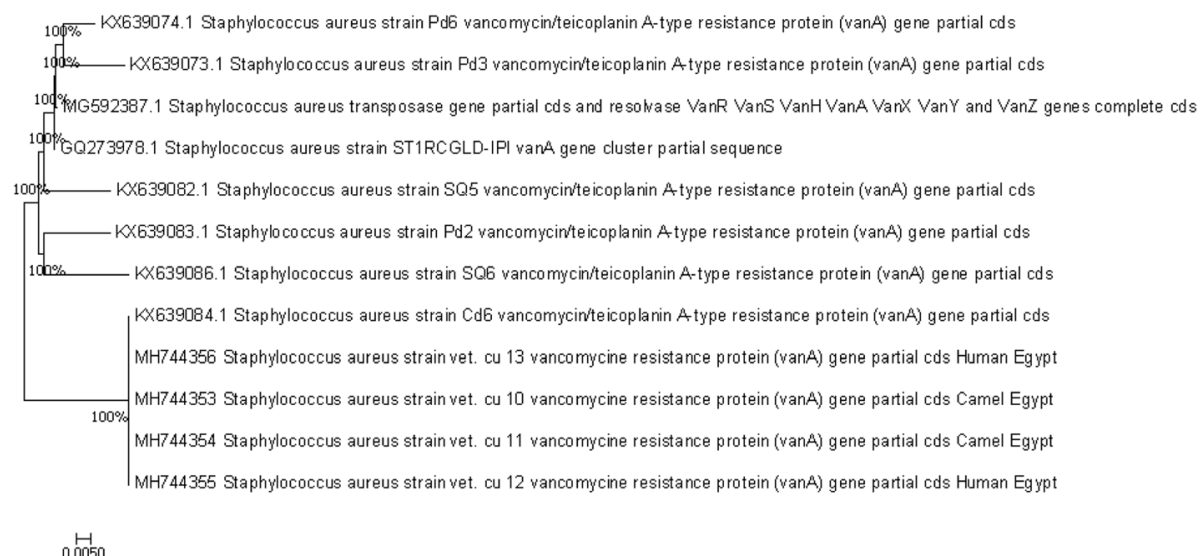

Fig. 5 Neighbour joining tree showing the relationship between the nucleotide sequences of the partial coding regions of VanA gene of $S$. aureus. The Evolutionary analysis was performed with MEGA version 7

and OXA. The mecA gene was amplified from all phenotypically FOX-, OXA- and VAN-resistant isolates (Fig. 2). Consequently, there has been concern about the emergence of $S$. aureus strains with decreased susceptibility to VAN.

Although VRSA strains were thought to be rare until recently [22], the present study on the occurrence of VRSA strains in Egypt revealed an increased rate of VRSA isolates. The overall VRSA prevalence was confirmed in $27.6 \%(8 / 29)$ and $54.5 \%(6 / 11)$ of the total dromedary camel and human $S$. aureus isolates, respectively (Tables 3,4$)$.

Similarly, MRSA was isolated from mastitic femal camels in one study [7] and from camel meat in another study [6]. Moreover, livestock-associated MRSA (LAMRSA) has been previously detected in the siblings of farmers who were in contact with animals [23], suggesting a potential risk for zoonotic transmission to contacts [24]. In addition, other previous studies showed the acquisition of LA-MRSA from handling meat in Hong Kong [25, 26].

To our knowledge, the prevalence of VRSA has never been investigated among camels in Egypt, which makes it difficult to compare our results with previous data from Egypt.

In this study, we found five VRSA strains with high levels of resistance to VAN (MIC $64 \mu \mathrm{g} / \mathrm{ml}$ ): two isolated from camel meat and three isolated from human. The alarmingly high value of these resistant strains and the high prevalence of VRSA strains is of special public health concern (Table 4).

One of the expected mechanisms of VAN resistance in $S$. aureus is the conjugative transfer of plasmids containing Tn1546 and thus the vanA gene cluster from VANresistant Enterococcus spp. (VRE) [11]. Moreover, vanB has not been reported for staphylococci thus far.
In this study, we evaluated the presence of $v a n A$ and $v a n B$ genes in VAN-resistant $S$. aureus isolates and found that all VAN-resistant isolates harboured both $v a n A$ and $v a n B$ genes (Figs. 3, 4). The analysis of the $v a n A$ gene sequences from isolates from camel meat and human revealed that they were identical to each other, suggesting the zoonotic importance of this pathogen and/or horizontal gene transfer.

In general, VRSA in livestock may come from visceracontaminated meat during slaughter or from the hands of employees in slaughterhouses, and colonization could pose a potential risk for zoonotic disease transmission $[24,27]$. Most of these types of contamination events are of greater concern in Asia and Africa than in Europe, the USA, and Canada [28].

VRSA was isolated from infected or colonized individuals in Turkey and Asiatic countries [29-31]. In Egypt, VRSA strains were not isolated from asymptomatic individuals but were isolated from $4.5 \%$ of clinical samples (patients with evident bacterial cutaneous infection) [32]. Clinical infections could result in a major source of community-acquired VRSA in Egypt.

Although the anterior nares are usually the primary site to screen for S. aureus, $90 \%$ of human nasal carriers also present colonization on their hands [33].

The clear limitation of this study was the lack of nasal swabs from the camels and nasal swabs from the workers; the latter would have been important with respect to VRSA colonization and the risk for further spread among human. Another limitation was the lack of clonal characterization of the VRSA strains isolated from human and animals. Further study based on whole genome sequencing with subsequent core-genome multilocus sequence typing (cg/MLST) is planned in collaboration with an international lab to assess/clarify the zoonotic transmission of $S$. aureus in the camel abattoirs. 


\section{Conclusion}

The present study reported the presence of VRSA in camel meat and human in contact with camels in Egypt.

Our research is the first in Egypt to report VRSA in camels, and we urge further comprehensive molecular epidemiological surveillance studies on the extent and potential zoonotic transmission of VRSA in livestock animals. Urgent interventions to control the transmission of these antibiotic-resistant organisms in abattoirs are needed.

\section{Abbreviations}

CHL: Chloramphenicol; CLI: Clindamycin; ERY: Erythromycin; FOX: Cefoxitin; NV: Novobiocin; OFX: Ofloxacin; OXA: Oxacillin; SXT: Trimethoprimsulfamethoxazole; VAN: Vancomycin

\section{Acknowledgements}

The authors would like to thank all the slaughterhouse workers in the investigated Egyptian abattoirs for their kind cooperation during sample collection

\section{Authors' contributions}

All authors contributed to the collection of samples, the molecular detection of the target genes, the analysis and interpretation of the data, as well as writing the manuscript. All authors read and approved the final manuscript.

\section{Funding}

The authors declare that they did not receive any funding or grants to support their research.

\section{Availability of data and materials}

All data generated or analysed during this study are included in this published article.

\section{Ethics approval and consent to participate}

The study was conducted according to ethical guidelines approved by the Faculty of Veterinary Medicine, Cairo University. There were no experiments on human participants.

\section{Consent for publication}

Not applicable.

\section{Competing interests}

The authors declare that they have no competing interests.

\section{Author details}

'Department of Microbiology, Faculty of Veterinary Medicine, Cairo University, PO Box 12211, Cairo, Egypt. ²Department of Food Safety and Biotechnology, Regional Center for Food and Feed, Agricultural Research Center, Giza, Egypt. ${ }^{3}$ Department of Animal Hygiene, Zoonoses and Animal Behaviour and Management, Faculty of Veterinary Medicine, Suez Canal University, Ismailia 41522, Egypt. ${ }^{4}$ Department of Dermatology, Venereology and Andrology, Faculty of Medicine, Alazhar University, Cairo, Egypt. ${ }^{5}$ Department of Zoonoses, Faculty of Veterinary Medicine, Cairo University, PO Box 12211, Giza, Cairo, Egypt.

Received: 6 February 2019 Accepted: 25 July 2019

Published online: 05 August 2019

\section{References}

1. Weese JS, Duijkeren VE. Methicillin-resistant Staphylococcus aureus and Staphylococcus pseudintermedius in veterinary medicine. Vet Microbiol. 2009; 140:418-29.

2. Lowly FD. Staphyloccoccus aureus infections. N Engl J Med. 1998;339:520-32

3. CDC Centers for Disease Control and Prevention. Staphylococcus aureus resistant to vancomycin--United States. MMWR Morb Mortal Wkly Rep. 2002:51:565.

4. Graveland H, Duim B, van Duijkesen E, Heederick D, Nagernaar JA. Livestock- associated methicillin Staphylococcus aureus in human and animals. Int J Med Microbiol. 2011;301:630-1.
5. El Harrak M, Faye B, Bengoumi M. Main pathologies of camels, breeding of camels, constraints, benefits and perspectives; 2011. p. 1-6. Conf. OlE

6. Quddoumi SS, Bdour SM, Mahasneh AM. Isolation and characterization of methicillin-resistant Staphylococcus aureus from livestock and poultry meat. Ann Microbiol. 2006;56:155-61.

7. Alzohairy MA. Colonization and antibiotic susceptibility pattern of methicillin resistance Staphylococcus aureus (MRSA) among farm animals in Saudi Arabia. J Bacteriol Res. 2011;3:63-8.

8. Quinn PJ, Markey BK, Carter ME, Donnelly WJ, Leonard FE. Veterinary microbiology and microbial disease. 1st ed. lowa: Blackwell Publishing Professional; 2002. p. 461-4.

9. Louie L, Goodfellow J, Mathieu P, Glatt A, Louie M, Simor AE. Rapid detection of methicillin-resistant staphylococci from blood culture bottles by using a multiplex PCR assay. J Clin Microbiol. 2002;40:2786-90.

10. CLSI. Performance standards for antimicrobial disk and dilution: susceptibility tests for bacteria isolated from animals. Clin Lab Stand Inst. 2016:28:M31-3.

11. Saadat S, Solhjoo K, Norooz-Nejad MJ, Kazemi A. VanA and vanB positive vancomycin-resistant Staphylococcus aureus among clinical isolates in Shiraz, South of Iran. Oman Med J. 2014;29:335

12. Azimian A, Havaei SA, Fazeli $H$, Naderi M, Ghazvini K, Samiee SM, et al. Genetic characterization of a vancomycin-resistant Staphylococcus aureus isolate from the respiratory tract of a patient in a university hospital in northeastern Iran. J Clin Microbiol. 2012;50(11):3581-5.

13. Cain CL. Antimicrobial resistance in staphylococci in small animals. Vet Clin North Am Small Anim Pract. 2013:43:19-40.

14. Armand-Lefevre L, Ruimy R, Andremont A. Clonal comparison of Staphylococcus aureus isolates from healthy pig farmers, human controls, and pigs. Emerg Infect Dis. 2005;11:711-4.

15. Beyene T, Hayishe H, Gizaw F, Beyi FA, Abunna F, Mammo B, Ayana D, Waktole $H$, Abdi DR. Prevalence and antimicrobial resistance profile of Staphylococcus in dairy farms, abattoir and humans in Addis Ababa, Ethiopia. BMC Res Notes. 2017;10:171

16. Mai-siyama IB, et al. Methicllin-resistant Staphylococcus aureus (MRSA) colonization rate among ruminant animals slaughtered for human consumption and contact persons in Maiduguri, Nigeria. Afr J Microbiol Res. 2014;8:2643-9.

17. World Health Organization. Antimicrobial Resistance: Global Report on Surveillance. Geneva; 2014. https://www.who.int/drugresistance/documents/ surveillancereport/en/. Accessed 30 Aug 2016

18. Kimang'a AN. A situational analysis of antimicrobial drug resistance in Africa: are we losing the battle? Ethiop J Health Sci. 2012;22:135-43.

19. Kumar A, Kaushik P, Anjay Kumar P, Kumar M. Prevalence of methicillinresistant Staphylococcus aureus skin and nasal carriage isolates from bovines and its antibiogram. Vet World. 2017;10:593-7.

20. Wijesekara PNK, Kumbukgolla WW, Jayaweera JAAS, Rawat D. Review on usage of vancomycin in livestock and humans: maintaining its efficacy, prevention of resistance and alternative therapy. Vet Sci. 2017;4:6. https:// doi.org/10.3390/vetsci4010006.

21. David MZ, Daum RS. Treatment of Staphylococcus aureus infections. Curr Top Microbiol Immunol. 2017:409:325-83.

22. Shekarabi M, Hajikhani B, Salimi Chirani A, Fazeli M, Goudarzi M. Molecular characterization of vancomycin-resistant Staphylococcus aureus strains isolated from clinical samples: a three year study in Tehran, Iran. PLoS One. 2017:12(8):e0183607.

23. Benito D, Lozano C, Rezusta A, Ferrer I, Vasquez MA, Ceballos S, Zarazaga M, Revillo MJ, Torres C. Characterization of tetracycline and methicillin resistant Staphylococcus aureus strains in a Spanish hospital: is livestock-contact a risk factor in infections caused by MRSA CC398? Int J Med Microbiol. 2014;304:1226-32.

24. Juhász-Kaszanyitzky E, Jánosi S, Somogyi P, Dán A, van der Graaf-van Bloois $L$, van Duijkeren E, Wagenaar JA. MRSA transmission between cows and humans. Emerg Infect Dis. 2007;13:630-2.

25. Ho J, O'Donoghue MM, Boost MV. Occupational exposure to raw meat: a newly-recognized risk factor for Staphylococcus aureus nasal colonization amongst food handlers. Int J Hyg Environ Health. 2014;217:47-53.

26. Boost M, Ho J, Guardabassi L, O'Donoghue M. Colonization of butchers with livestock-associated methicillin-resistant Staphylococcus aureus. Zoonoses Public Health. 2013:60:572-6.

27. Lee $\mathrm{JH}$. Methicillin (oxacillin)-resistant Staphylococcus aureus strains isolated from major food animals and their potential transmission to humans. Appl Environ Microbiol. 2003;69:6489-94. 
28. Pexara A, Solomakos N, Govaris A. Prevalence of methicillin-resistant Staphylococcus aureus in milk and dairy products. J Hellenci Vet Med Soc. 2013;64(1):17-34.

29. Cesur S, Irmak H, Simşek H, Cöplü N, Klıç H, Arslan U, Bayramoğlu G, Baysan BO, Gülay Z, Hoşoğlu S, Berktaş M. Evaluation of antibiotic susceptibilities and VISA-VRSA rates among MRSA strains isolated from hospitalized patients in intensive care units of hospitals in seven provinces of Turkey. Mikrobiyol Bul. 2012;46(3):352-8.

30. Saha B, Singh AK, Ghosh A, Bal M. Identification and characterization of a vancomycin-resistant Staphylococcus aureus isolated from Kolkata (South Asia). J Med Microbiol. 2008;57(1):72-9.

31. Pahadi PC, Shrestha UT, Adhikari N, Shah PK, Amatya R. Growing resistance to vancomycin among methicillin resistant Staphylococcus aureus isolates from different clinical samples. JNMA J Nepal Med Assoc. 2014;52(196):977-81.

32. ElSayed N, Ashour M, Amine AE. Vancomycin resistance among Staphylococcus aureus isolates in a rural setting, Egypt. Germs. 2018;8(3):134.

33. Wertheim HF, Melles DC, Vos MC, van Leeuwen W, van Belkum A, Verbrugh HA, Nouwen JL. The role of nasal carriage in Staphylococcus aureus infections. Lancet Infect Dis. 2005;5:751-62.

\section{Publisher's Note}

Springer Nature remains neutral with regard to jurisdictional claims in published maps and institutional affiliations.

Ready to submit your research? Choose BMC and benefit from:

- fast, convenient online submission

- thorough peer review by experienced researchers in your field

- rapid publication on acceptance

- support for research data, including large and complex data types

- gold Open Access which fosters wider collaboration and increased citations

- maximum visibility for your research: over $100 \mathrm{M}$ website views per year

At BMC, research is always in progress.

Learn more biomedcentral.com/submissions 